\title{
Microscopic Characterization of Electrodeposited Mg Layers for Battery Application
}

Mukesh Bachhav ${ }^{1}$, Emily Nelson ${ }^{2}$, Adam Crowe ${ }^{2}$, Bart Bartlett ${ }^{2}$, Nathan Hahn $^{3}$, Kevin Zavadil ${ }^{3}$, PengWei Chu ${ }^{1}$, Emmanuelle A. Marquis ${ }^{1}$

${ }^{1}$ Department of Materials Science and Engineering, University of Michigan, Ann Arbor 48109. MI, USA

${ }^{2}$ Department of Chemistry, University of Michigan, Ann Arbor 48109-1055, MI, USA

${ }^{3}$ Advanced Materials Laboratory, Sandia National Laboratories, Albuquerque, NM, 87185 USA

Magnesium has been considered as a strong candidate for metal air battery applications due its low cost, environmentally benignity, high theoretical specific charge capacity $(2.205 \mathrm{Ah} / \mathrm{g}$ ), and high theoretical energy density $\left(3.8 \mathrm{Ah} / \mathrm{cm}^{3}\right)$ [1, 2]. However, one of the current technical limitations is the understanding of the interactions taking place at the electrolyte/Mg interface. In this study, atom probe tomography (APT) and transmission electron microscopy (TEM) have been successfully applied to the characterization of electrodeposited $\mathrm{Mg}$ layers to understand the functionality of electrolytes in $\mathrm{Mg}$ deposition.

Mg layers were deposited in a series of electrolytes using a standard 3 electrode cell with working electrode as $\mathrm{Au}$ coated-Si wafer, counter electrode as $\mathrm{Mg}^{0}$, and reference electrode as $\mathrm{Mg}^{0}$. The compositions of the electrodeposited $\mathrm{Mg}$ layers were investigated using atom probe tomography to understand the role of electrolyte functionality in the deposition of $\mathrm{Mg}$. The three electrolytes used were $(\mathrm{PhMgCl})_{4}-\mathrm{Al}(\mathrm{OPh})$ (APCC) [3], 2 $\mathrm{MgCl}_{2}: \mathrm{AlCl}_{3}$ (MACC) [4], both in tetrahydrofuran, and $\mathrm{Mg}$ $\left(\mathrm{CF}_{3} \mathrm{SO}_{2} \mathrm{NSO}_{2} \mathrm{CF}_{3}\right)_{2}$ (TFSI) in diglyme to explore the effect of electrolyte chemistry. The morphology, structure and chemistry of the deposited $\mathrm{Mg}$ layers will be discussed. The deposited films are almost pure $\mathrm{Mg}$ (>98 at\%) with impurities that include $\mathrm{O}, \mathrm{C}, \mathrm{Al}, \mathrm{Cl}, \mathrm{MgH}_{\mathrm{X}}, \mathrm{MgO}_{\mathrm{X}}$. The amount of impurity is slightly lower for MACC electrolyte, while the other two electrolytes yield significant of hydroxide and impurity incorporation. Compositions of $\mathrm{Mg}$ layers obtained from the three electrolytes are shown in Table 1.

Efficient $\mathrm{Mg}$ deposition/dissolution using a Grignard-based electrolyte is commonly ascribed to the absence of a surface film, which would impact anode performance. The nucleation and growth mechanisms of $\mathrm{Mg}$ grains during deposition are important mechanisms to understand to ensure longterm stability of rechargeable Mg batteries. To investigate the interactions with possible surface films, analyses were carried out on Mg layers, for which deposition had been interrupted for some controlled amount of time [5] to let the surface equilibrate with the electrolyte. A TEM cross-section image (Fig. 1a) illustrates the two layers of $\mathrm{Mg}$ formed during the interrupted deposition using MACC. APT analysis indicates the presence of $\mathrm{C}, \mathrm{Al}, \mathrm{Al}$, and $\mathrm{Mg}$ oxides/hydrides at the interface (Fig. 1b). Our understanding of the role of the surface film in governing the re-nucleation of $\mathrm{Mg}$ onto itself will be discussed in this presentation.

\section{References:}

[1] T. Zhang, Z. Tao, J. Chen, Materials Horizons, 1 (2014) 196-206.

[2] F. Cheng, J. Chen, Chemical Society Reviews, 41 (2012) 2172-2192.

[3] E.G. Nelson, J.W. Kampf, B.M. Bartlett, Chemical Communications, 50 (2014) 5193-5195. 
[4] R.E. Doe, R. Han, J. Hwang, A.J. Gmitter, I. Shterenberg, H.D. Yoo, N. Pour, D. Aurbach, Chemical Communications, 50 (2014) 243-245.

[5] Nathan T. Hahn, P.G. Kotula, David Wetzel, Marvin Malone, Ralph G. Nuzzo, and Kevin R. Zavadil, Submitted to J Phys Chem C

[6] This work was supported as part of the Joint Center for Energy Storage Research an Energy Innovation Hub funded by the U. S Department of Energy, Office of Science, Basic Energy Sciences

Table 1: Measured compositions (in at.\%) of electrodeposited $\mathrm{Mg}$ films deposited using APCC$(\mathrm{PhMgCl})_{4}-\mathrm{Al}(\mathrm{OPh})_{3}, \mathrm{MACC}-2 \mathrm{MgCl}_{2}: \mathrm{AlCl}_{3}$, and TFSI-Mg $\left(\mathrm{CF}_{3} \mathrm{SO}_{2} \mathrm{NSO}_{2} \mathrm{CF}_{3}\right)_{2}$

\begin{tabular}{|c|c|c|c|}
\hline Elements/ions & TFSI & MACC & APCC \\
\hline $\mathrm{Mg}$ & $98.2 \pm 0.3$ & $99.6 \pm 0.2$ & $98.3 \pm 0.3$ \\
\hline $\mathrm{C}, \mathrm{O}, \mathrm{Cl}, \mathrm{MgH}_{\mathrm{x}}, \mathrm{MgO}_{\mathrm{x}}$ & $1.8 \pm 0.3$ & $0.4 \pm 0.2$ & $1.6 \pm 0.2$ \\
\hline
\end{tabular}
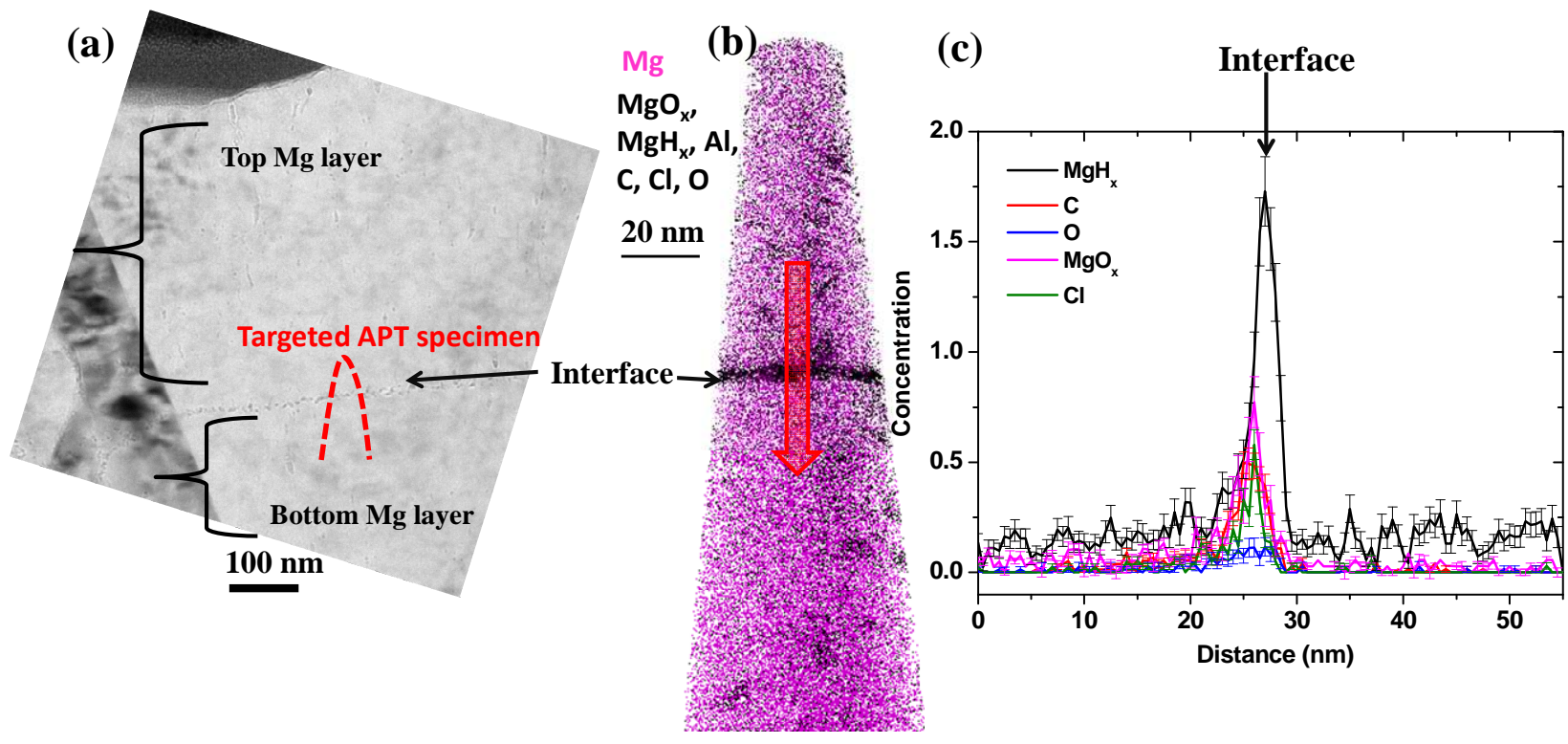

Figure 1: TEM image showing two distinct Mg layers marked with site targeted by APT. (b) 3-D reconstruction showing interface and distribution of $\mathrm{Mg}$ and impurities. (c) 1D distribution profile taken along interface from top layer to bottom layer 